\title{
IZBRANI ELEMENTI SOCIALNOGEOGRAFSKE PREOBRAZBE LJUBLJANE
}

\author{
Dejan Rebernik*
}

\begin{abstract}
Izvleček
$V$ prispevku so predstavljeni nekateri najizrazitejši procesi socialnogeografske preobrazbe Ljubljane. $V$ ta namen so na osnovi primerjave popisnih podatkov za leti 1981 in 1991 in ob uporabi modela faktorske ekologije identificirani procesi preobrazbe socioekonomskega, družinskega in etničnega položaja prebivalstva. $V$ Ljubljani poteka intenzivna socialnogeografska preobrazba, ki jo označujejo predvsem pospešena prostorska socialna diferenciacija prebivalstva, suburbanizacija mestnega obrobja, citizacija, reurbanizacija in gentrifikacija mestnega središča, staranje prebivalstva po posameznih delih mesta, etnična segregacija in podobno.
\end{abstract}

Ključne besede: Urbana geografiija, socialnogeografska preobrazba, socioekonomski položaj prebivalstva, družinski položaj prebivalstva, etnični položaj prebivalstva, Ljubljana

\section{SELECTED ELEMENTS OF SOCIALGEOGRAPHIC \\ TRANSFORMATION OF LJUBLJANA}

\begin{abstract}
In the following report some of the most obvious processes of socialgeographic transformation of Ljubljana are being represented. On the basis of comparison of inventory data for the year 1981 and 1991 and with application of a model of factor ecology, processes of transformation of socioeconomic, family and ethnic situation of inhabitants are being identified. Intensive socialgeographic transformation is being executed in Ljubljana, characterized mostly by faster spatial social differentiation of inhabitants, suburbanization of city margin, citization, reurbanization and gentrification of city center, aging of inhabitants from particular parts of city, ethnical segregation, and similar.
\end{abstract}

Key words: Urban geography, sociogeographical transformation, socioeconomic status, family status, ethnical status, Ljubljana

\footnotetext{
* Mag., Oddelek za geografijo, Filozofska fakulteta, Univerza v Ljubljani, Aškerčeva 2, SI 1000 Ljubljana
} 


\section{UVOD}

$\mathrm{V}$ prispevku poskušamo identificirati in orisati nekatere najznačilnejše in najpomembnejše procese, ki preoblikujejo socialnogeografsko zgradbo Ljubljane. $\mathrm{V}$ ta namen smo na osnovi primerjave popisnih podatkov za leti 1981 in 1991 in ob uporabi modela faktorske ekologije identificirali procese preobrazbe socioekonomskega, družinskega in etničnega položaja prebivalstva.

Osnovno teoretsko izhodišče raziskave nam predstavlja faktorska ekologija, kot so jo v šestdesetih letih razvili ameriški geografi Murdie, Sweetser, Berry in Rees. Kasneje so faktorsko analizo teoretsko dopolnili in na številnih empiričnih primerih uporabljali avtorji po vsem svetu. Največ raziskav je bilo opravljenih na primeru severnoameriških in zahodnoevropskih mest, $\mathrm{v}$ manjšem številu pa so zastopana tudi mesta iz preostalih delov sveta. Faktorska analiza se naslanja na analizo socialnih območij avtorjev Shevky, Williams in Bell iz prve polovice petdesetih let (Shevky in Williams, 1949 ter Shevky in Bell, 1955). Faktorska ekologija je kasneje doživela številne kritike, toda kljub temu ostaja $\mathrm{v}$ središču zanimanja in akademskih razprav. Prav gotovo je najbolj uporabljano teoretsko metodološko izhodišče pri socialnogeografskem proučevanu mest (Knox, 1987, s. 126). Zanimivo je, da med slovenskimi geografi in na primeru slovenskih mest faktorska ekologija takorekoč ni bila prisotna.

Jedro faktorske ekologije je ugotovitev, da lahko socialno geografijo mesta oziroma njegovo socialnogeografsko zgradbo ponazorimo s tremi osnovnimi komponentami : ekonomskim položajem, družinskim položajem in etničnim položajem prebivalstva. $\mathrm{V}$ faktorski ekologiji lahko torej socialno in prostorsko diferenciacijo mestnega prebivalstva najbolje opišemo in pojasnimo s tremi dejavniki : socio-ekonomskim položajem prebivalstva, družinskim položajem oziroma položajem v življenskem ciklusu in etničnim oziroma nacionalnim, jezikovnim ali rasnim položajem prebivalstva. V številnih empiričnih raziskavah se je izkazalo, da omenjene tri komponente najbolje pojasnijo socialnogeografsko zgradbo anglosaških mest (Severna Amerika, Avstralija, Nova Zelandija, Velika Britanija). Za mesta v zahodni in srednji Evropi se je izkazalo, da socialno in prostorsko diferenciacijo prebivalstva najbolje opišemo s socio-ekonomskim položajem, v manjši meri tudi s družinskim statusom, da pa se etnični status pogosto ne pojavlja kot samostojna komponenta in je "vključen" v prvi dve (Knox, 1987, s. 132). V kasnejših raziskavah so omenjene tri komponetne avtorji vsebinsko dopolnili in jim dodali nekatere nove. Zaradi spremenjenih razmer in vloge ter pomena družine je največ sprememb doživela komponenta družinski status, zato številni avtorji povdarjajo, da bi bil ustreznejši naziv "življenski slog" (Knox, 1987).

Izkazalo se, da je v primeru Ljubljane socioekonomski položaj prebivalstva določen $\mathrm{z}$ izobrazbeno in poklicno strukturo ter dohodki prebivalcev, posredno tudi $\mathrm{Z}$ 
stanovanjskim standardom. Etnični položaj prebivalstva v prvi vrsti določa nacionalna in verska struktura prebivalstva. Dovolj pričakovano pa je le-ta povezana tudi s specifično poklicno in izobrazbeno strukturo prebivalstva, ki jo označuje nizko izobražena in nekvalificirana delovna sila. Družinski status prebivalstva pa določata starostna struktura prebivalstva, struktura gospodinjstev in $\mathrm{z}$ njima povezano naravno gibanje prebivalstva. Na podlagi tega lahko zaključimo, da se rezultati naše raziskave zelo dobro ujemajo z ugotovitvami faktorske ekologije. Tudi dejstvo, da je $\mathrm{v}$ našem primeru heterogen etnični položaj prebivalstva povezan $\mathrm{z}$ neugodno poklicno in izobrazbeno sestavo prebivalstva je skladno $\mathrm{z}$ ugotovitvami faktorske ekologije. Značilno je namreč, da se predstavniki etničnih manjšin pogosto uvrščajo med nižje socialne sloje prebivalstva.

Kot socialnogeografsko transformacijo mesta razumemo vse tiste procese, ki povzročajo spremembe v socialnogeografski zgradbi urbanega prostora. Sodobna socialnogeografska zgradba mesta je rezultat takšnih procesov. Naš namen je izluščiti in orisati tiste, ki so najpomebneje vplivali na oblikovanje socialne geografije Ljubljane. V urbanogeografski literaturi avtorji največ pozornosti posvečajo procesom kot so suburbanizacija, citizacija, gentrifikacija, socialna degradacija in podobno.

Mesto in njegova socialnogeografska zgradba je $\mathrm{v}$ stalni preobrazbi, zato lahko govorimo o mestu kot o procesu (Schaffer, 1971). Socialnogeografska transformacija urbanega prostora je neposredno povezana $\mathrm{z}$ ostalimi vidiki mestne preobrazbe - rast in prostorsko širjenje širjenje mesta, spremembe $\mathrm{v}$ rabi tal, spremembe $\mathrm{v}$ vrednosti zemljišč in podobno. Seveda je socialnogeografska preobrazba mesta vpeta $\mathrm{v}$ splošni okvir procesov, ki spreminjajo družbo v celoti. Tako v Sloveniji v devetdesetih letih poteka intenzivno socialno razslojevanje prebivalstva, ki se kaže predvsem $\mathrm{v}$ vedno večjih razlikah v dohodkih in premoženju med posameznimi sloji prebivalstva. Tako se po eni strani veča delež prebivalstva s podpovprečnimi dohodki, narašča pa tudi sloj premožnega prebivalstva. Značilen je tudi proces staranja prebivalstva, ki je predvsem posledica upadanja rodnosti, naraščanja smrtnosti in zmanjšanega priseljevanja iz območij nekdanje Jugoslavije. Takšni procesi se nedvomno odražajo tudi $\mathrm{v}$ mestnem prostoru $\mathrm{z}$ vedno večjo socialnogeografsko, $\mathrm{v}$ prvi vrsti socioekonomsko diferenciacijo mesta ter preobrazbo družinskega ter etničnega položaja prebivalstva.

Intenzivnost in hitrost socialnogeografske preobrazbe mesta je močno odvisna od stopnje in intenzivnosti prostorske mobilnosti prebivalstva znotraj mesta. Le ta je pogojena s številnimi dejavniki, od ekonomskih in socialnih do kulturnih. Na splošno velja, da je interurbana prostorska mobilnost višja v razvitejših družbah. Osnovni pogoj za veliko prostorsko mobilnost prebivalstva je prav gotovo razvit neprimičninski trg, ki ljudem omogoča izbiro najustreznejšega stanovanja glede na materialne možnosti. Intenzivnost prostorske mobilnosti prebivalstva je pogojena tudi $\mathrm{z}$ nekaterimi drugimi dejavniki, kot na primer tradicijo in bivalnimi navadami ter 
lastniško strukturo nepremičnin. Tako je na primer prostorska mobilnost prebivalstva v ZDA mnogo višja kot v Zahodni Evropi, kljub izenačeni gospodarski razvitosti. V ZDA se letno preseli 15 do $20 \%$ gospodinjstev. To je predvsem posledica dejstva, da je v ZDA kar $90 \%$ stanovanj lastniških. V Evropi je stopnja mobilnosti gospodinjstev mnogo nižja in se giblje med 5 in $10 \%$ (Knox, s. 285). Velike so tudi razlike med posameznimi mesti. Tako je na primer število preseljenih na 1000 prebivalcev za leto 1980 v Berlinu 116, v Dublinu pa le 20. Nepremičninski trg je skoraj v celoti prepuščen tržnim zakonitostim. Na drugi strani je $\mathrm{v}$ evropskih državah velik del stanovanjskega fonda "izključen" iz tržnih pritiskov (Housing in Europe, s. 13), kar prav gotovo zavira prostorsko mobilnost prebivalstva. Za Slovenijo je značilna nizka stopnja prostorske mobilnosti prebivalstva. Podatki so dosegljivi le za mobilnost prebivalstva med občinami, ki pa lahko služijo kot ocena splošne prostorske mobilnost, tudi znotraj mesta. Kljub majhni mobilnosti prebivalstva pa v slovenskih mestih potekajo nekateri procesi, ki povzročajo spremembe $\mathrm{v}$ socialnogeografski zgradbi urbanega prostora. Med temi procesi je prav gotovo najizrazitejša suburbanizacija. Suburbanizacija pa seveda ne povzroča le spremeb v številu prebivalstva po posameznih delih mesta in obmestja, temveč odločilno vpliva na socialnogeografsko transformacijo urbanega prostora. Na primeru Ljubljane bomo poskušali identificirati tiste elemente socialnogeografske preobrazbe mesta, ki so neposredno povezani s suburbanizacijo.

Termin suburbanizacija se je v slovenski geografski literaturi uveljavil dokaj pozno, čeprav je problematika odnosov med mestom, obmestjem in podeželjem že dalj časa $\mathrm{v}$ ospredju pozornosti mnogih avtorjev (na primer Vladimir Kokole, Vladimir Klemenčič in Igor Vrišer). V zadnjem času se je s problematiko suburbanizacije največ ukvarjal Marjan Ravbar, ki jo razume kot prostorsko preobrazbo obmestij, ki jo pogojuje ekonomski napredek in spremebne $\mathrm{v}$ sistemu vrednot med mestom in podeželjem (Ravbar, 194, s. 105). V kontekstu proučevanja socialnogeografske preobrazbe Ljubljane vidimo suburbanizacijo kot proces prostorske mobilnosti prebivalstva (selitev iz osrednjega dela mesta $\mathrm{v}$ obmestje), rezultat katerega je tudi spremenjena socialnogeografska zgradba mesta.

Proces citizacije $\mathrm{v}$ urbani geografiji označujemo kot kopičenje terciarnih in kvartarnih, predvesm poslovnih in oskrbnih dejavnosti $\mathrm{v}$ mestnem središču, $\mathrm{s}$ tem povezano izseljevanje prebivalstva, dnevne migracije delovne sile in spremebe $\mathrm{v}$ fiziognomiji in rabi tal. $V$ kontekstu naše raziskave citizacijo, $v$ povezavi z ostalimi procesi, razumemo kot enega od vzrokov socialnogeografske preobrazbe zgradbe mestnega središča.

S pojmom reurbanizacija se označuje proces ponovnega povečevanja števila prebivalstva $\mathrm{v}$ mestnem središču in drugačnega vrednotenja tega dela mesta, kar ima za posledico prostorsko in socialnogeografsko transformacijo. Omenjeni pojav je značilen za severnoameriška in zahodnoevropska mesta. Na osnovi ugotovitev naše 
raziskave pa je prisoten tudi $\mathrm{v}$ Ljubljani. Z reurbanizacijo je neposredno povezana gentrifikacija. Izraz se je uveljavil predvsem v anglosaški urbani geografiji, označuje pa proces invazije srednjega in višjega sloja prebivalstva $\mathrm{V}$ območja $\mathrm{s}$ slabim socioekonomskim položajem, ob sočasni fizični prenovi in socialni transformaciji degradiranih mestni predelov.

Socialna degradacija vključuje cel niz procesov, rezulat katerih je oblikovanje območij s slabim socioekonomskim položajem prebivalstva oziromo socialno degradiranih območij, ki ga spremlja fizično propadanje stanovanjskega fonda, pojav kriminala in delinkvence ter koncentracija posameznih marginalnih socialnih skupin prebivalstva. V slovenskih razmerah je socialna degradacija posameznih delov mest prav gotovo prisotna, čeprav ne dosega tako ekstremnih oblik kot v nekaterih drugih okoljih.

\section{PROCESI PREOBRAZBE SOCIOEKONOMSKEGA POLOŽAJA PREBIVALSTVA}

V Ljubljani je prostorska socioekonomska diferenciacija prebivalstva relativno močna. Posebno velika so odstopanja med območji z najugodnejšim in najslabšim socioekonomski položajem prebivalstva : na eni strani novejši del mestnega središča, vilske četrti in nadstandardne soseske enodružinskih hiš in na drugi strani podstandarna naselja enodružinskih hiš na mestnem obrobju, starejše delavske četrti in posamezne povojne blokovne soseske. $\mathrm{V}$ preostalih delih mesta je socioekonomska sestava prebivalstva bolj heterogena.

S pomočjo primerjave podatkov za popisni leti 1981 in 1991 lahko identificiramo nekatere osnovne procese in spremembe $\mathrm{v}$ socioekonomskem položaju prebivalstva $\mathrm{v}$ Ljubljani. Ti procesi so $\mathrm{v}$ veliki meri povezani s socioekonomsko in demografsko preobrazbo slovenske družbe v celoti, deloma pa so specifični za Ljubljano. Na prvem mestu bi lahko izpostavili terciarizacijo. Tako se zmanjšuje delež zaposlenih $v$ sekundarnih dejavnostih na račun rasti deleža zaposlenih v terciarnih in kvartarnih dejavnosti. Omenjeni proces je v Ljubljani še posebno izrazit, saj se je med leti 1981 in 1991 delež zaposlenih v sekundarnih dejavnostih iz preko $40 \%$ zmanšal na $26 \%$. $\mathrm{S}$ terciarizacijo so neposredno povezane tudi spremembe $\mathrm{v}$ poklicni in izobrazbeni strukturi prebivalstva.

Iz podatkov v tabeli 1 je razvidno, da se je izobrazbena struktura prebivalstva med opazovanima letoma opazno izboljšala, na kar kaže povečan delež prebivalstva $s$ srednjo in univerzitetno izobrazbo na račun zmanjšanja deleža prebivalstva brez izobrazbe oziroma $\mathrm{z}$ nedokončano ali končano osnovno šolo. Podobno se je izboljšala strokovna izobrazba, kar se kaže predvsem v zmanjšanem deležu nekvalificiranih delavcev in povečanem deležu delavcev s srednjo, višjo ali visoko strokovno 
izobrazbo. Primerjava med leti 1981 in 1991 pokaže na trend zmanjševanja deleža industrijskih in upravnih delavcev na račun povečanja deleža strokovnjakov in trgovcev. To je skladno s splošno terciarizacijo slovenske družbe. V nasprotju s tem pa je delež storitvenega osebja ostal na enaki ravni.

Tabela 1 : Izobrazbena struktura prebivalstva v Mestni občini Ljubljana

\begin{tabular}{|l|c|c|c|}
\hline & $1981 \%$ & $1991 \%$ & $81 / 91$ \\
\hline brez šolske izobrazbe & 0.9 & 0.4 & 44.4 \\
\hline nedokončana osnovna šola & 12.1 & 7.9 & 65.2 \\
\hline osnovna šola & 26.4 & 22.8 & 86.3 \\
\hline nižja izobrazba & 39.4 & 31.1 & 78.9 \\
\hline srednja šola & 44.3 & 48.8 & 110.1 \\
\hline srednja izobrazba & 44.3 & 48.8 & 110.1 \\
\hline višja šola & 4.7 & 6.8 & 144.7 \\
\hline visoka šola & 10.4 & 11.5 & 110.6 \\
\hline univerzitetna izobrazba & 15.1 & 18.3 & 121.1 \\
\hline nekvalificirani delavci & 23.1 & 16.0 & 69.2 \\
\hline kvalificirani delacvi & 26.5 & 28.1 & 105.7 \\
\hline nižja strokovna izobrazba & 6.3 & 1.9 & 30.1 \\
\hline srednja strokovna izobrazba & 24.4 & 30.4 & 124.5 \\
\hline višja strovna izobrazba & 5.9 & 9.5 & 161.0 \\
\hline visoka strokovna izobrazba & 13.8 & 16.2 & 117.3 \\
\hline
\end{tabular}

Tabela 2 : Poklicna struktura prebivalstva v Mestni občini Ljubljana

\begin{tabular}{|l|c|c|c|}
\hline & $1981 \%$ & $1991 \%$ & $1981 / 91$ \\
\hline kmetijski delavci & 0.9 & 0.8 & 88.8 \\
\hline industrijski delavci & 31.4 & 27.5 & 87.5 \\
\hline storitveno osebje & 7.9 & 7.8 & 98.7 \\
\hline trgovci & 7.2 & 9.1 & 126.4 \\
\hline upravni delavci & 21.5 & 19.4 & 90.2 \\
\hline strokovnjaki & 23.1 & 27.2 & 117.7 \\
\hline vodilni delavci & 4.3 & 4.6 & 106.9 \\
\hline
\end{tabular}

Podrobnejša prostorska analiza pokaže, da so omenjeni procesi v posameznih delih mesta potekali z različno intenzivnostjo. Gre za tako imenovana prehodna območja z visoko mobilnostjo prebivalstva. Iz teorije urbane geografije je poznano, da so to predvsem starejši deli mesta s slabšimi bivalnim razmerami, ki privlačijo predvsem priseljence z nižjim socialnim statusom. V primeru Ljubljane je poleg starega mestnega središča in starejših delavski predmestij visok delež priseljenih značilen še za 
podstandardne soseske enodružinskih hiš (Rakova Jelša, Zeleni log, Tomačevo...) in za nekatere blokovske soseske.

Izobrazbena in poklicna struktura prebivalstva se je posebno močno spremenila na mestnem obrobju. Močno se je povečal delež strokovnjakov in vodilnih delavcev ter delež prebivalcev s srednjo in univerzitetno izobrazbo. Močno se je izboljšala tudi strokovna izobrazba prebivalstva. Izboljšanje socioekonomskega položaja prebivalstva lahko povežemo predvsem $\mathrm{s}$ suburbanizacijo in preseljevanjem prebivalstva iz osrednjega dela mesta, predvsem pa iz blokovskih sosesk, na mestno obrobje. Le ta je zajela v prvi vrsti prebivalstvo z višjim socioekonomskim položajem. Novi "priseljenci" so tako bistveno spremenili socialnogeografsko zgradbo mestnega obrobja, za katerega so značilne določene polruralne poteze, kot na primer nadpovprečen delež kmetijskih in industrijskih delavcev in podpovprečen socioekonomski položaj prebivalstva. Posebno izstopajo območja najintenzivnejše rasti prebivalstva, kot so Gameljne, Črnuče, Tacen, Podutik, Kozarje, obrobje Barja, Sostro, Podmolnik in podobno. V naštetih delih mesta nastajajo predvsem nadstandardne soseske enodružinskih hiš, kamor se naseljuje prebivalstvo z dobrim socioekonomskim položajem.

Proces izboljševanja socioekonomskega položaja prebivalstva je značilen tudi za posamezne dele mestnega središča, in sicer za staro mestno središče in Tabor. Na to kaže močan porast prebivalcev $\mathrm{z}$ univerzitetno izobrazbo in vodilnih delavcev. Zanimivo je, da je na Taboru upadel delež strokovnjakov in porastel delež storitvenega osebja. Zadnji popisni podatki iz leta 1991 seveda ne zajemajo najnovejših sprememb v socialnogeografski zgradbi tega dela mesta, ko so bile le te najintenzivnejše. Gre za tiste dele mestnega središča, ki v nasprotju s splošno tendenco upadanja števila prebivalstva v središču mesta izkazujejo rast števila prebivalstva. V Stari Ljubljani se je z obnovo pridobilo nova kvalitetna stanovanja $\mathrm{v}$ katera se naseljuje prebivalstvo $\mathrm{z}$ višjim socioekonomskim položajem. Na Taboru poteka gradnja novih stanovanjskih objektov z nadstandardnimi stanovanji. V primeru obeh omenjenih delov mestnega središča bi lahko govorili o reurbanizaciji, to se pravi ponovnem naraščanju števila prebivalstva $\mathrm{v}$ mestnem središču po daljšem obdobju upadanja - vse od začetka 20. stoletja. Poleg naraščanja števila prebivalstva je prisotna tudi socioekonomska transformacija. Za staro mestno središče in vzhodni, nekoč industrijski del mestnega središča je značilen relativno slab socioekonomski položaj prebivalstva, ki se kaže v slabši izobrazbeni in poklicni strukturi, nizkih dohodkih in predvsem $\mathrm{v}$ slabem stanovanjskem standardu. Z obnovo stanovanjskega fonda in novogradnjami so nova nadstandardna stanovanja, tudi zaradi lokacije v mestnem središču, postala zanimiva za ljudi z višjim socioekonomskim položajem. Ob sprostitivi nepremičninskega trga in ureditvi lastninsko pravnih razmer lahko pričakujejo nadaljevanje in okrepitev tega procesa. Opisani proces bi lahko primerjali $\mathrm{z}$ gentrifikacijo, procesom socioekonomske transformacije socialno degradiranih predelov mest $\mathrm{v}$ ZDA in Zahodni Evropi. Za mestna središča so tako značilna zelo velika nasprotja med območji z nizkim in visokim socioekonomskim položajem prebivalstva, ki ležijo v neposredni bližini. Gre torej za zelo heterogeno 
socialnogeografsko zgradbo. Po mnenju večine avtorjev gentrifikacijo povzročata dve med seboj povezani sili : na eni strani povpraševanje po kvalitetnih stanovanjih $\mathrm{v}$ mestnem središču in po drugi strani ekonomski interes nepremičninskih družb. Prednosti lokacije $\mathrm{v}$ mestnem središču so najbolj privlačne za mlajše, pogosto neporočene profesionalce, zaposlene $\mathrm{v}$ mestnem središču. Visoki dobički pri prodaji obnovljenih ali novih stanovanj $\mathrm{v}$ mestnem središču so vzpodbudili mnoge nepremičninske družbe, da so $\mathrm{z}$ obnovo sanirale degradirane predele $\mathrm{v}$ mestnem središču. Tudi v primeru Ljubljane bi lahko govorili o gentrifikaciji določenih delov mestnega središča. Socialna diferenciacija je sicer manj izrazita, tako da socialna in fizična degradacija ni nikoli dosegla takšnega obsega kot $\mathrm{v}$ mestih ZDA in Zahodne Evrope. Tudi razlike v socialnogeografski zgradbi posameznih delov mestnega središča so mnogo manjše. Toda $v$ osnovnih značilnostih je proces socioekonomske preobrazbe, ki je bil identificiran $\mathrm{v}$ Ljubljani, soroden procesu gentrifikacije. Tako se v območja $\mathrm{z}$ relativno slabim socioekonomskim položajem prebivalstva in $\mathrm{Z}$ starejšim, podstandardnim stanovanjskim fondom naseljuje prebivalstvo $\mathrm{z}$ višjimi dohodki. Glavni nosilec obnove in gradnje novih stanovanj so različna gradbena in druga podjetja. Povpraševanje po novih ali obnovljenih stanovanjih $\mathrm{v}$ mestnem središču Ljubljane je izredno veliko, tako da so cene nepremičnin močno nadpovprečne, kar investitorju zagotavlja visok dobiček. Najbolj značilno območje gentrifikacije je nekdanje industrijsko obrobje mestnega središča med železniško postajo in Metelkovo, Kotnikovo in Slomškovo ulico - "Novi Tabor", posamezni deli starega mestnega središča, posebno na Mestnem trgu, Zgornje Poljane in podobno.

Na osnovi primerjave popisnih podatkov za leti 1981 in 1991 ne moremo določiti nobenega območja, kjer bi se socioekonomski položaj prebivalstva opazno poslabšal. Na podlagi tega bi lahko sklepali, da v Ljubljani noben del mesta ne doživlja izrazite socialne degradacije, to se pravi koncentracije prebivalstva z nizkim socioekonomskim statusom ter raznih marginalnih skupin. Toda ob splošnem izboljšanju izobrazbene strukture prebivalstva ter upadanju deleža industrijskih delavcev, določeni deli mesta izkazujejo stagnacijo oziroma celo rahlo poslabšanje. To velja za večino blokovskih sosesk, zlasti Štepanjsko naselje, Nove Fužine, Dravlje, sosesko Komandanta Staneta, Bratovževo in Glinškovo ploščad, Nove Stožice, v manjši meri pa tudi za starejše blokovske soseske v Šiški in za Bežigradom. Naštete soseske izkazujejo stagnacijo ali rahlo povišanje deleža prebivalstva z nižjo izobrazbo, nekvalificiranih, kvalificiranih in industrijskih delavcev. Na drugi strani pa upada ali stagnira delež prebivalcev z univerzitetno izobrazbo, višjo ali visoko strokovno izobrazbo ter delež strokovnjakov. Posebno močno pa se je povečal delež nezaposlenih, saj indeks med leti 1981 in $1991 \mathrm{v}$ posameznih blokovskih soseskah dosega tudi vrednosti nad 500. Ti podatki opozarjajo, da se je $\mathrm{v}$ večjih blokovskih soseskah začel socioekonomski položaj prebivalstva poslabševati, tako da bi lahko govorili o začetku socialne degradacije. Odseljuje se prebivalstvo $\mathrm{z}$ višjo izobrazbo in višjimi dohodki, predvsem na mestno obrobje $\mathrm{v}$ enodružinske hiše $\mathrm{v}$ zelenem okolju. V soseskah ostaja socialno šibkejši sloj prebivalstva, upokojenci in nezaposleni. Z izrazitejšim socialnim razslojevanjem 
prebivalstva $\mathrm{v}$ devetdesetih letih se je proces, ki ga nakazujejo naši podatki, po vsej verjetnosti še okrepil. Tudi podatki o povečanju kriminala in drugih oblikah družbeno nesprejemljivega vedenja, kot so narkomanija ali prostitucija ali pa o koncentraciji posameznih marginalnih skupin prebivalstva (kar vse je značilno za socialno degradacijo) niso sistematično zbrani in dostopni. Na obseg in intenzivnost socialne degradacije lahko posredno sklepamo tudi iz fizičnega propadanja stanovanjskih stavb in splošne neurejenosti okolja $\mathrm{v}$ posameznih soseskah. Ob tem se postavlja vprašanje vzdrževanja in obnove stanovanjskih zgradb in skupnih površin, za katero so z odkupom družbenih stanovanj prevzeli odgovornost novi lastniki. Zaradi nizkih dohodkov je ustrezno vzdrževanje zelo vprašljivo, kar bo povzročilo nadaljne fizično propadanje stavb in okolja. To pa bo spodbudilo tudi socialno degradacijo.

\section{PROCESI PREOBRAZBE DRUŽINSKEGA STATUSA PREBIVALSTVA}

Ob relativno nizki prostorski mobilnosti prebivalstva je glavni dejavnik preobrazbe družnskega položaja prebivalstva po posameznih delih mesta proces staranja in prehajanja skozi zaporedne faze $\mathrm{v}$ življenskem ciklusu. To je še posebno očitno na primeru blokovskih sosesk z relativno homogeno starostno strukturo prebivalstva. Tako je $\mathrm{v}$ novejših delih mesta starostna struktura prebivalstva odvisna predvsem od časa nastanka soseske. V novozgrajena stanovanja so se naselile v prvi vrsti mlade družine, ki so nato prehajale skozi zaporedne faze $\mathrm{v}$ življenskem ciklusu : mladi pari brez otrok mlade družine z otroci - zrele družine z odraslimi otroci - odselitev otrok. Gre torej za tipično "staranje" prebivalstva po posameznih delih mesta, ob šibki prostorski mobilnosti le tega. Tako je za starejše blokovske soseske zgrajene $\mathrm{v}$ petdesetih in šestdeseih letih značilno ostarelo prebivalstvo (visok delež starejše in starejše srednje generacije), za soseske zgrajene $\mathrm{v}$ sedemdesetih prevlada srednje generacije in $\mathrm{v}$ najmlajših soseskah prevlada mladih družin. Starostna struktura naštetih delov mesta je torej relativno homogena. Opisan proces je značilen predvsem za večje blokovske soseske in soseske enodružinskih hiš in je bil mogoč tudi zaradi stalnega priseljevanje mladega prebivalstva iz območij nekdanje Jugoslavije in preostale Slovenije. Zaradi močno zmanjšanega priseljevanja lahko v prihodnosti pričakujemo, da se podoben trend ne bo nadaljeval.

Opisani proces potrjujeje tudi primerjava med deleži posameznih starostnih skupin za leti 1981 in 1991. V desetletju med leti 1981 in 1991 se je tako delež starejšega prebivalstva močno povečal $\mathrm{v}$ najstarejših blokovskih soseskah iz petdesetih in šestdesetih let v Šiški, za Bežigradom in v Mostah. Staranje prebivalstva spremlja tudi povečevanje deleža samskih gospodinjstev in deleža družin brez otrok. Delež starejše srednje generacije se je povečal v soseskah zgrajenih v sedemdesetih letih (na primer Štepanjsko naselje, soseska Komandanta Staneta, Bratovževa in Glinškova ploščad, Koseze, Murgle) in delež mlajše srednje generacije ter otrok v soseskah iz osemdesetih let, kamor so se naselile mlade družine (Fužine, Dravlje, Nove Stožice...). 
Med procesi, ki kljub omenjeni "nemobilnosti" spreminjajo družinski položaj prebivalstva, velja omeniti predvsem suburbanizacijo. Kot je bilo ugotovljeno, se je suburbanizacija začela $\mathrm{v}$ drugi polovici sedemdesetih let, okrepila pa se je $\mathrm{v}$ osemdesetih in devetdesetih letih. Razseljevanje prebivalstva iz mestnega središča in celotnega osrednjega dela mesta, predvsem blokovskih sosesk, na mestno obrobje, se je v tem obdobju zelo razmahnilo. Na mestnem obrobju se je močno povečal delež starejše srednje generacije med 50 in 64 leti starosti. Iz tega lahko zaključimo, da je suburbanizacija zajela predvsem to starostno skupino, ki je finančno najmočnejša.

Zelo zanimiva pa je dinamika starostne strukture prebivalstva $\mathrm{v}$ mestnem središču. Označuje jo močan porast deleža mladih družin (mlajše srednje generacije in otrok), predvsem v starem mestnem središču, deloma tudi v novejšem delu mestnega središča in upadanje deleža starejše in starejše srednje generacije. To potrjuje tudi povečanje povprečne velikosti gospodinjstev in upad deleža samskih gospodinjstev. Očitno je torej, da je staranje prebivalstva v mestnem središču že doseglo "vrhunec". Ob visoki smrtnosti starega prebivalstva se v izpraznjena stanovanja selijo njihovi potomci, dediči. Prisoten je tudi pojav odselitve ostarelih gospodinjstev v manjše stanovanje oziroma na mestno obrobje. Razlogi so različni: citizacija mestnega središča in s tem povezano odseljevanje prebivalstva ali pa odselitev zaradi spremenjenih potreb in bivalnih želja. Pogosto starši prepustijo stanovanje v centru mesta svojim potomcem, sami pa se preselijo v mirnejše okolje na mestnem obrobju. Naraščanje deleža mladih družin lahko pripišemo tudi novogradnjam $\mathrm{v}$ mestnem središču (na primer med Kotnikovo in Metelkovo ulico) in postopnemu obnavljanju stanovanjskega fonda ter prodaji stanovanj na trgu, kar potrjuje tudi izredno močno povečanje deleža mlajše srednje generacije in otrok v KS Tabor in Stara Ljubljana. Del mestnega središča s slabšim socioekonomskim položajem prebivalstva in slabšim stanovanjskim standardom (na primer Stari in Gornji trg ter Zgornje Polajne) pa je tradicionalno območje priseljevanja prebivalstva nižjega sloja, za katero je značilna prevlada mlajše generacije in nadpovprečno število otrok.

Zaključimo lahko z ugotovitvijo, da je družinski položaj prebivalstva v stalnem procesu preobrazbe, ki je v primeru Ljubljane v mnogo večji meri rezultat "inercije" in procesa staranja prebivalstva določenih delov mesta kot pa prostorske mobilnosti pogojene $\mathrm{s}$ spremenjenim položajem v življenskem ciklusu. Vzroki za takšno stanje so različni. V preteklosti je prostorsko mobilnost prav gotovo zaviral visok delež "družbenih" stanovanj, kjer so imeli stanovalci takoimenovano stanovanjsko pravico, ki je ni bilo mogoče "prenesti" na drugo stanovanje. Posledica tega je bil nerazvit nepremičninski trg. Z odkupom družbenih stanovanj ter bistvenim povečanjem deleža lastniških stanovanj ter spremembo družbeno-ekonomskega sisema pa je prišlo do sprostitve le tega, kar pomeni, da lahko $\mathrm{v}$ prihodnosti pričakujemo večjo prostorsko mobilnost prebivalstva. Razlogi za prostorsko nemobilnost prebivalstva v slovenskih mestih so gotovo tudi sociopsihološki. Menjava stanovanja je povezana z določenimi stroški, ki se jim želi gospodinjstvo izogniti. Posebno nemobilno je starejše prebivalstvo, ki noče 
zapustiti znanega bivalnega in socialnega okolja in ostaja $\mathrm{v}$ pogosto (pre)velikih stanovanjih.

Najopaznejši procesi preobrazbe starostne strukture prebivalstva so torej staranje prebivalstva $\mathrm{v}$ blokovskih soseskah in na mestnem obrobju ter pomlajevanje prebivalstva v mestnem središču.

\section{PROCESI PREOBRAZBE ETNIČNEGA POLOŽAJA PREBIVALSTVA}

Med leti 1981 in 1991 se je delež neslovenskega prebivalstva povečal iz 17.7 \% na 21.8 \%. Posebno močno se je povečal delež Muslimanov, v manjši meri tudi Srbov, zmanjšal pa se je delež Hrvatov. Očitno je torej, da je dinamika priseljevanja neslovensklega prebivalstva $\mathrm{v}$ Ljubljano različna po posameznih nacionalnih skupinah. $\mathrm{V}$ devetdesetih letih pa se je priseljevanje iz območij nekdanje Jugoslavije iz političnih in gospodarskih razlogov močno zmanjšalo. Dinamika deleža neslovenskega prebivalstva pa se močno razlikuje tudi po posameznih delih mesta. V desetletju med leti 1981 in 1991 je največi porast deleža neslovenskega prebivalstva značilen za novejše blokovske soseske (Nove Fužine, Črnuče, Dravlje, Vič - Bonifika, Bežigrad - Rapova jama), del mestnega središča (predvsem predeli s slabšimi bivalnimi pogoji), južno obrobje mesta, kamor se je usmerila indivdualna, pogosto nelegalna in podstandardna gradnja ter del Bežigrada, za katerega je značilna koncentracija samskih domov in vojaških stanovanj. Nadpovprečno povečanje deleža neslovenskega prebivalstva v posameznih delih mesta je rezultat priseljevanja prebivalstva iz območij nekdanje Jugoslavije $v$ osemdesetih letih in tudi preseljevanja neslovenskega prebivalstva znotraj mesta. Novi priseljenci, katere praviloma označuje nizek socioekonomski položaj, se naseljujejo predvsem $\mathrm{v}$ območja, ki nudijo cenejše oblike bivanja. V primeru Ljubljane so to v prvi vrsti starejša degradirana območja mesta, kot so staro mestno središče in starejša delavska predmestja s podstandardnimi stanovanji (na primer Zgornje Poljane). Del novih priseljencev si problem bivanja reši z individualno gradnjo. Pogosto gre za "črno" gradnjo, brez ustreznih gradbenih dovoljen ter brez priključitve na komunalno, vodovodno in električno omrežje. Na ta način nastajajo barakarska naselja ali pa naselja grajenih hiš z zelo nizkim stanovanjskim standardom. Najnovejše naselje takšnega tipa je nastalo na Rakovi Jelši, južno od avtoceste. Del neslovenskega prebivalstva si je z izboljšanjem socioekonmskega položaja oziroma ob dodelitvi socialnega stanovanja naselil v novonastajajočih blokovskih soseskah. $\mathrm{V}$ blokovske soseske so se naseljevali tako novi priseljenci, kot tudi priseljenci iz barakarskih in podstandardnih naselij. V osemdesetih letih je bil v Ljubljani iz barakarskih naselij preseljen velik del prebivalstva, povečini $v$ socialna družbena stanovanja. Večino prebivastva barakarskih naselij je predstavljalo neslovensko prebivalstvo, tako da je njihova sanacija oziroma odstranitev močno spremenila etnično zgradbo mesta. 


\section{ZAKLJUČEK}

Zaključimo lahko z ugotovitvijo, da v Ljubljani poteka intenzivna socialnogeografska preobrazba. Le ta je $\mathrm{v}$ prvi vrst odraz nekaterih splošnih procesov, ki spreminjajo slovensko družbo : socioekonomsko razslojevanja prebivalstva, upadanje rodnosti in posledično staranje prebivalstva, umiritev priseljevanja neslovenskega prebivalstva in podobno. Našteti procesi vplivajo na pospešeno socialno prostorsko diferenciacijo mesta $\mathrm{v}$ smeri oblikovanja homogenih socialnih območij $\mathrm{z}$ značilno socialnogeografsko zgradbo. Mestno obrobje označuje predvsem intenzivna suburbanizacija, rezultat katere je izboljševanje socioekonomskega položaja prebivalstva. $\mathrm{V}$ mestnem središču vzporedno poteka citizacija in $\mathrm{z}$ njo povezano zmanjševanje števila prebivalstva ter reurbanizacija in gentrifikacija, ki ju spremlja tudi povečevanje deleža mlajše in srednje generacije. Za povojne soseske večstanovanjskih hiš je značilno staranje prebivalstva, v posameznih soseskah pa je mogoče zaznati začetke socialne degradacije.

$\mathrm{V}$ povezavi z nadaljnim pospešenim socialnim razslojevanjem in povečano prostorsko mobilnostjo prebivalstva lahko pričakujemo povečano prostorsko socioekonomsko diferenciacijo in oblikovanje relativno homgenih socialnih območij.

\section{LITERATURA}

- Bakšič Ksenja : Socialno - prostorna segregacija stanovništva Zagreba, Geografski Horizont, broj 2, godina XL, 1994

- Brevar Gojmir : Kategorije mestnih četrti s šibko socialno strukturo v mestih Slovenije, Časopis za kritiko znanosti 19 - 20, Ljubljana, 1977

- Carter Harold : The Study of Urban Geography, Arnold, 1995

- Črnivec Živka : Kulturna podoba marginalne družbe na obrobju mesta Ljubljane (študija naselja Tomačevo), Ljubljana, 1975

- Gobec, Ljubo : Stanovanjsko barakarstvo v Ljubljani, Časopis za kritiko znanosti 19 - 20, Ljubljana, 1977

- Housing in Europe, Housing Research Conference in Denmark, European Network for Housing Research, 1997

- Knox, Paul : Urban Social Geography, Longman Scientific and Technical, 1995

- Krivic, Blaž : Socialno deformirani predeli Ljubljane na območju občin Ljubljana Bežigrad in Ljubljana - Moste, Časopis za kritiko znanosti 19 - 20, Ljubljana, 1977

- Kucler Slavica : Barakarska naselja v Ljubljani, Ljubljana - Glasilo mestne občine Ljubljana, št.6/7, 1998

- Natek Milan : Delovna sila iz drugih republik Jugoslavije v Sloveniji in posebej v Ljubljani, Geografski zbornik XI, Ljubljana 1969

- Pak Mirko : Socialnogeografski problemi deformacij stanovanjske strukture v mestih, Časopis za kritiko znanosti 19 - 20, Ljubljana, 1977 
- Pak Mirko in Bervar, Gojmir : Geografski učinki socialne deformacijev nekaterih predelih slovenskih mest, GV XLIII, Ljubljana, 1971

- Ravbar Marjan : Kvaliteta življenja in kvaliteta bivalnaga okolja Ljubljane : Spremljanje in vrednotenje suburbanizacijskih procesov, Kvaliteta življenja in kvaliteta bivalnega okolja, Razvojno - raziskovalni projekt za potrebe mesta Ljubljane, Delovno poročilo 1. faze projekta, Urbanistični inštitit Slovenije, 1994

\title{
SELECTED ELEMENTS OF SOCIALGEOGRAPHIC TRANSFORMATION OF LJUBLJANA
}

\begin{abstract}
Summary
Some of the most significant and most important processes are represented in the article, which are transforming the socialgeographical structure of Ljubljana. On the basis of comparison of inventory data for the year 1981 and 1991 and with application of a model of factor ecology, we have identified for this purpose processes of transformation of socioeconomic, family and ethnical position of inhabitants.

Socioeconomic position of inhabitants is determined by their educational, professional and financial structure. In Ljubljana socioeconomic differentiation of inhabitants is relatively strong. Deviations are particularly large among areas with the most satisfactory and the worse socioeconomic position of inhabitants: newish part of the city center, villadoms and over-standard neighborhoods of one-family houses on one side and under-standard settlements of one-family houses on city's skirt, oldest working-class districts and some postwar neighborhoods of block of flats on the other side. In other parts of the city socioeconomic structure of inhabitants is much more heterogeneous. Transformation of socioeconomic situation of inhabitants is characterized mostly with bigger and bigger differences among single parts of the city. City skirt is strongly influenced by suburbanization, which is fastening socialgeographic transformation of this part of the city. It is accompanied by significant improvement of socioeconomic situation of inhabitants as well as growing of share of middle generation. In central part of central business center intensive citization is taking place, however in particular parts of city center beginning of the process of reurbanization and gentrification is obvious.
\end{abstract}

Family situation of inhabitants is being determined mostly by age structure of inhabitants and by structure of households. Regarding relatively low spatial mobility of inhabitants main factor of transformation of family situation of inhabitants in different parts of the city represent aging process and living through successive phases of life cycle. This is particularly obvious on the example of neighborhoods of blocks of flats with relatively homogeneous age structure of inhabitants. One of the 
processes which are changing family situation of inhabitants despite of the afore stated immobility, which should be pointed out, is suburbanization. Share of older middle generation between age of 50 and 64 has strongly increased on the city skirt. Therefore we can conclude that suburbanization has included particularly the said age group. However dynamic of age structure of inhabitants of the city center is very interesting. It is characterized by strong increase of share of young families (younger middle generation and children), in old city center in particular, partly also in newly part of the city center, as well as decrease of part of older and older middle generation. Therefore aging of inhabitants in the city center has obviously already reached the "peak."

Share of non-Slovene inhabitants increased between year 1981 and 1991 from 17,7\% to $21,8 \%$. Share of Muslims increased significantly, share of Serbs increased for a lower degree, however share of Croatian decreased. Dynamic of immigration of nonSlovene inhabitants into Ljubljana obviously varies regarding single national groups. In the decade from 1981 and 1991 stronger increase of the share of non-Slovene inhabitants is significant for the newly neighborhoods of blocks of flats, where individual, usually illegal and under-standard building concentrated. Over-average increase of the share of non-Slovene inhabitants in particular parts of the city results from immigration of inhabitants from the areas of former Yugoslavia in the eighties as well as immigration of non-Slovene inhabitants inside the city. New immigrants, characterized by the rule with low socioeconomic position, are mostly settling in areas which offer cheaper possibilities of dwelling.

Intensive socialgeographical transformation is taking place in Ljubljana. It is mostly reflection of some general processes which are changing Slovene society: socioeconomic declassification of inhabitants, decrease of fertility and consequently aging of inhabitants, slowing down of immigration of non-Slovene inhabitants, and similar. Stated processes have influence on faster social spatial differentiation of the city in the direction of formation of homogeneous social areas with significant socialgeographic structure. 